\title{
Kombinasi Metode Certainty Factor dan Forward Chaining untuk Identifikasi Jenis Kulit Wajah Berbasis Android
}

\author{
Syavira Cahyaningsih, Agung Triayudi", Ira Diana Sholihati \\ Fakultas Teknologi Komunikasi dan Informatika, Sistem Informasi, Universitas Nasional, Jakarta, Indonesia \\ Email: 1viracahya91@gmail.com, 2,*agungtriayudi@civitas.unas.ac.id,3,*iradiana2803@gmail.com \\ Email Penulis Korespondensi: agungtriayudi@ civitas.unas.ac.id
}

\begin{abstract}
Abstrak-Menggunakan skincare dan melakukan perawatan kulit wajah harus sesuai dengan jenis kulit wajah, karena jika tidak sesuai dapat menimbulkan masalah seperti kulit wajah breakout, kulit kering, kulit iritasi, dan kulit berjerawat. Untuk mengetahui jenis kulit wajah harus melakukan pemeriksaan dengan dokter spesialis kulit dan kelamin, akan tetapi mahalnya biaya konsultasi dan panjangnya proses antrian menjadi kendala setiap orang. Maka dari itu penulis membuat sistem pakar untuk mengidentifikasi jenis kulit wajah menggunakan kombinasi metode certainty factor dengan teknik forward chaining. Hasil diagnosa dari perhitungan menggunakan aplikasi sistem pakar dan hasil perhitungan manual dari salah satu data reponden dari 100 data responden yaitu menghasilkan tingkat keyakinan yang sama, masing-masing menghasilkan persentase sebesar 99.45\% dan hasil diagnosa menyatakan bahwa pengguna memiliki jenis kulit normal.
\end{abstract}

Kata Kunci: Android; Certainty Factor; Forward Chaining; Kulit Wajah; Sistem Pakar

Abstract-Using skincare and facial skin care must be in accordance with the type of facial skin, because if it is not suitable, it can cause problems such as facial skin breakouts, dry skin, irritated skin, and acne prone skin. To find out the type of facial skin, you have to do an examination with a skin and genital specialist, but the high cost of consultation and the long queue process is an obstacle for everyone. Therefore, the authors created an expert system to identify facial skin types using a combination of certainty factor methods with forward chaining techniques. The diagnostic results from calculations using an expert system application and the results of manual calculations from one of the respondent data from 100 respondent data, namely producing the same level of confidence, each of which produces a percentage of $99.45 \%$ and the diagnostic results state that the user has a normal skin type.

Keywords: Android; Certainty Factor; Expert System; Facial Skin; Forward Chaining

\section{PENDAHULUAN}

Kulit merupakan salah satu bagian tubuh yang memiliki sifat elastis untuk melindungi tubuh manusia dari pengaruh lingkungan.[1] Animo sebagian besar orang menginginkan kulit wajah sehat dan bebas dari penyakit kulit terutama jerawat. Maka dari itu, setiap individu harus melakukan perawatan wajah dan menggunakan beberapa produk yang sesuai dengan kulit wajah. [2]

Helena Rubinstein mengklaim ada empat jenis kulit wajah yaitu kulit sensitif, kulit kombinasi, kulit berminyak, dan juga kulit kering.[3] Mengetahui jenis kulit merupakan dasar sebelum melakukan rutinitas perawatan pagi dan malam hari karena melakukan perawatan yang dipakai harus sesuai dengan jenis kulit wajah setiap orang.[4] Dokter spesialis kulit dan dokter kecantikan sangat diperlukan untuk menentukan jenis kulit wajah yang nantinya dapat menggunakan produk perawatan serta melakukan treatment yang sesuai dan sudah ditentukan oleh dokter tersebut. [5] Mahalnya biaya konsultasi dan panjangnya proses antrian menjadi menjadi kendala seseorang untuk mengetahui jenis kulit wajah. Selain itu kebanyakan orang enggan bertanya kepada dokter spesialis kulit maupun dokter kecantikan karena terbatasnya jumlah dokter spesialis kulit dan dokter kecantikan.[6] Maka dari itu penulis membuat sistem pakar dengan mengkombinasi metode certainty factor dengan teknik forward chaining yang dapat mengidentifikasi jenis kulit yang dapat berfungsi layaknya seorang pakar sedang mendiagnosa pasien.

Dalam dunia kesehatan sudah banyak sistem terkomputerisasi yang dibangun dan dirancang untuk membantu dalam efisiensi kerja. Seperti halnya sistem pakar digunakan untuk memecahkan berbagai macam masalah, contohnya saat ahli pakar memiliki halangan. Pengetahuan dalam sistem pakar bisa dari berbagai sumber seperti seorang ahli, buku, majalah dan orang yang mempunyai ahli dalam bidang tertentu.[7]

Penelitian terkait sistem pakar diagnosa jenis kulit wajah diantaranya Penelitian yang dilakukan Yovita dkk pada tahun 2020. Setiap orang yang menginginkan kulit sehat dan bersih tetapi melakukan perawatan wajah yang tidak sesuai dengan jenis kulit yang menyebabkan timbulnya masalah baru pada kulit wajah. Penelitian Yovita dkk memiliki tujuan untuk mengidentifikasi jenis kulit wajah berbasis website dengan menggunakan metode certainty factor. Penelitian tersebut menghasilkan bahwa penentuan jenis kulit wajah yang dilakukan menggunakan sistem $91 \%$ sudah sesuai dengan pakar kulit.[8]

Penelitian berikutnya mengenai analisis perancangan untuk mengidentifikasi jenis kulit wajah yang dilakukan Indyah dan Bina pada tahun 2019. Ahli kecantikan sangat penting dibutuhkan oleh setiap orang terutama perempuan karena ahli kecantikan dapat mengenali jenis kulit pada wajah di setiap orang dan memberi solusi secara tepat untuk melakukan perawatan sesuai jenis kulit. Maka diperlukan sistem pakar untuk mengenali jenis kulit pada wajah dengan menggunakan metode certainty factor. Hasil dari penelitian yang dilakukan responden 
perempuan menghasilkan 0.953344 untuk jenis kulit sensitif, 95\% sistem pakar diperlukan untuk mengetahui jenis kulit pada wajah dan hasil persentase dari sistem sudah sesuai sebanyak 98\%.[5]

Penelitian ketiga Indyah dan Bina pada tahun 2019 melakukan penelitian mengenai analisis perancangan sistem pakar tentang identifikasi jenis kulit wajah. Melakukan perawatan kulit harus sesuai dengan jenis kulit, untuk mengetahui jenis kulit harus menemukan dokter spesialis kulit tetapi untuk melakukan pemeriksaan dengan dokter kulit dibutuhkan biaya yang sangat mahal dan antrian dalam dokter kulit jumlahnya tidak sedikit, maka dari itu peneliti merancang sebuah sistem pakar terkomputerisasi dengan menggunakan metode certainty factor sebagai algoritma perhitungan.[6] Menghasilkan proses perancangan DAD, ERD, user interface , dan database sistem diawali dengan analisa dan diakhiri dengan tahap implementasi sehingga sistem pakar sesuai dengan kebutuhan.

Penelitian keempat tentang perancangan sistem pakar yang dilakukan Rangga Pebrianto dkk pada tahun 2020 untuk mengetahui jenis kulit wajah. Banyak jumlah konsumen melakukan konsultasi pada perusahaan Jafra yang menggunakan skincare tetapi tidak sesuai dengan jenis kulit sehingga menimbulkan efek buruk pada kulit wajah.[1] Peneliti membangun aplikasi sistem pakar dengan menggunakan metode certainty factor. Hasil dari penelitian tersebut aplikasi yang dirancang dapat menentukan jenis kulit wajah serta informasi tentang jenis kulit.

Penelitian kelima yang dilakukan oleh Young Bin Lee, dkk pada tahun 2019 yang meneliti tentang identifikasi jenis kulit khusus pria secara spesifik di Korea berdasarkan usia dan wilayah.[9] Penelitian ini menggunakan metode Baumann, ada 4 jenis kulit wajah pada metode Baumann yaitu: berminyak $(\mathrm{O})$ atau kering (D), sensitif (S) atau resisten (R), berpigmen (P) atau tidak berpigmen (N), dan berkerut (W) atau kencang (T). Hasil dari penelitian dengan melakukan survei kepada 1.000 pria di Korea dengan usia anta 20 tahun sampai dengan 60 tahun yang dikelompokkan berdasarkan usia dan wilayah jenis kulit O mendapatkan persentase 53,5\%, jenis kulit S 56,1\%, jenis kulit N 84,4\%, dan jenis kulit W 57,5\%. Dengan data tersebut membuktikan bahwa jenis kulit pria di Korea setiap wilayahnya berbeda-beda

Penelitian lain menentukan jenis kulit dan jerawat vulgaris yang dilakukan Tamba dan Jusuf pada tahun 2020.[10] Penelitian yang memiliki tujuan menemukan hubungan jenis kulit wajah dengan jerawat vulgaris dengan menggunakan metode cross-sectional penelitian dilakukan pada remaja terutama pada sekolah SMA Santo Thomas 1 Medan. Hasil dari 93 Siswa dengan melakukan pemeriksaan menggunakan kuesioner metode Baumann untuk mengidentifikasi jenis kulit menunjukkan bahwa 73 dari 93 siswa menderita jerawat vulgaris yang didominasi oleh perempuan dengan kelompok usia 15 tahun dan persentase jenis kulit 79,6\% memiliki kulit berminyak, maka dapat disimpulkan bahwa ada hubungan yang signifikan antara jenis kulit dengan jerawat vulgaris.

Berdasarkan dari jurnal penelitian sebelumnya, terdapat beberapa kekurangan dimana sistem yang digunakan hanya berbasis website bahkan ada beberapa yang berbasis desktop dan jurnal penelitian sebelumnya hanya menggunakan metode certainty factor. Maka dari itu penulis mengkombinasi metode certainty factor dengan teknik forward chaining dalam membangun sistem pakar untuk mengidentifikasi jenis kulit wajah dengan tujuan mengetahui jenis kulit wajah pada user dengan tingkat keyakinan berupa persentase, user juga dapat melihat solusi bahan dalam skincare, memberi tahapan perawatan secara tepat sesuai jenis kulit dan penulis menambahkan fitur artikel tentang pengetahuan kesehatan, kulit, dan juga makeup.

\section{METODOLOGI PENELITIAN}

Berikut Diagram tahapan penelitian yang dilakukan dalam proses penelitian, sehingga penelitian yang dilakukan berjalan dengan baik:

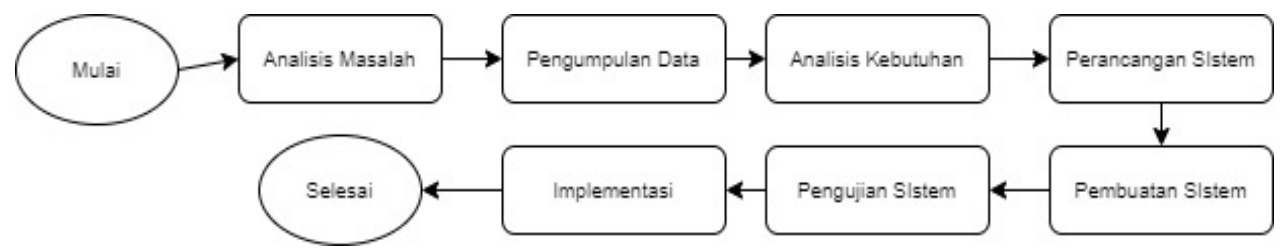

Gambar 1. Diagram tahapan penelitian

Berdasarkan gambar 1 tahapan penelitian dimulai dengan analisis masalah, dilanjutkan dengan pengumpulan data, analisis kebutuhan, perancangan sistem, pembuatan sistem, pengujian sistem, dan tahapan yang terakhir yaitu implementasi sistem.

\subsection{Analisis Masalah}

Analisis masalah adalah tahapan yang melakukan analisa masalah yang terjadi di sekitar lingkungan bahkan terjadi pada beberapa dokter kulit dan dokter aesthetic untuk menyelesaikan kasus dalam mengidentifikasi jenis kulit wajah serta menentukan solusi yang sesuai dengan jenis kulit dengan proses ketentuan yang berlaku sesuai dengan ahlinya yaitu dokter kulit. Hipotesa dari permasalahan, penulis memberi solusi dengan membangun aplikasi sistem pakar dengan menggabungkan metode certainty factor dengan teknik forward chaining berbasis android. 


\subsection{Pengumpulan Data}

Pada tahap ini, data dikumpulkan dengan melakukan studi pustaka dengan mengutip dari beberapa sumber bacaan yang terkait dengan penelitian. Selain itu penulis juga melakukan observasi dan wawancara kepada pakar tentang jenis kulit wajah dengan data yang dibutuhkan data jenis kulit, gejala setiap jenis kulit, solusi setiap jenis kulit, nilai certainty factor pakar dan nilai bobot [11][12].

Forward Chaining suatu algoritma dari dua metode reasoning saat menggunakan mesin untuk mengambil keputusan yang secara logis mendeskripsikan sistem looping yang berasal dari satu aturan interferensi serta argumen yang bersifat valid. [13]Pengertian lain dari forward chaining merupakan teknik untuk mencari suatu informasi berupa konklusi yang berasal dari fakta yang telah didapatkan dengan menyesuaikan kumpulan dari fakta-fakta tersebut. Apabila fakta sesuai dengan bagian $I F$, maka dapat dieksekusi rule tersebut. Apabila rule sudah diproses, maka fakta baru (THEN) ditambahkan ke basis data. Rule diawali dari yang teratas dan setiap rule hanya boleh melakukan eksekusi sekali [14].

Certainty Factor suatu faktor kepastian untuk membuktikan ketidakpercayaan pemikiran ahli pakar, dimana dalam menggambarkan tingkat kepercayaan pakar membutuhkan faktor kepastian, biasanya hasil dari metode faktor kepastian berupa persentase [15]. Certainty factor menggunakan nilai sebagai memperhitungan tingkat keyakinan seorang pakar terhadap suatu data [8].

Langkah-langkah perhitungan menggunakan metode certainty factor:

a. Menentukan CF Pararel

Certainty factor pararel merupakan $\mathrm{CF}$ yang didapat dari beberapa premis dalam sebuah aturan. Masing-masing premis dan operator dari premis, CF user mempengaruhi besarnya nilai CF sekuensial. CF user pada masingmasing premis didapat dengan pembobotan yang telah ditentukan oleh pakar.

b. Menentukan CF Sekuensial

CF sekuensial didapat dari hasil perhitungan CF pararel dalam satu aturan dengan CF (pakar) yang ditentukan oleh pakar. Berikut perhitungan CF sekuensial pada persamaan (1).

$$
C F(\text { pararel })=C F(\text { user }) \times C F(\text { pakar })
$$

c. Menentukan CF Gabungan

Merupakan CF akhir dari sebuah konklusi yang dipengaruhi oleh CF pararel dengan tingkat kepastian yang dihasilkan oleh sistem dalam menentukan diagnosa adalah CF gabungan yang dirumuskan pada persamaan (2) $[16]$

$$
C F_{(C F 1, C F 2)}=C F 1+C F 2 \times(1-C F 1)
$$

\subsection{Analisis Kebutuhan}

Tahap analisis kebutuhan, penulis menggunakan bebrapa perangkat keras dan perangkat lunak untuk membangun sistem pakar identifikasi jenis kulit wajah menggabungkan metode certainty factor dengan teknik forward chaining berbasis android.

\subsection{Perancangan Sistem}

Tahap perancangan sistem merupakan tahap determinasi dari beberapa proses dan data yang dibutuhkan dalam membuat sistem pakar berbasis android dengan menggabungkan metode certainty factor dengan teknik forward chaining berbasis android. Tahap perancangan bisa juga didefinisikan sebagai strategi dalam memecahkan masalah yang nanti akan menghasilkan suatu solusi terbaik bagi masalah tersebut.

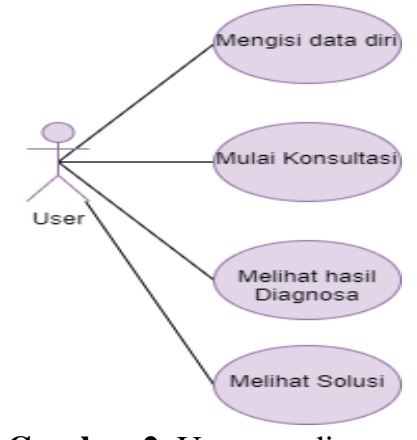

Gambar 2. Use case diagram

Pada Gambar 2, menggambarkan use case diagram sistem pakar untuk mengidentifikasi jenis kulit wajah yang menunjukan proses dari sistem serta menggambarkan fungsi sistem. Use case diagram yang terdiri dari satu aktor yaitu user. 


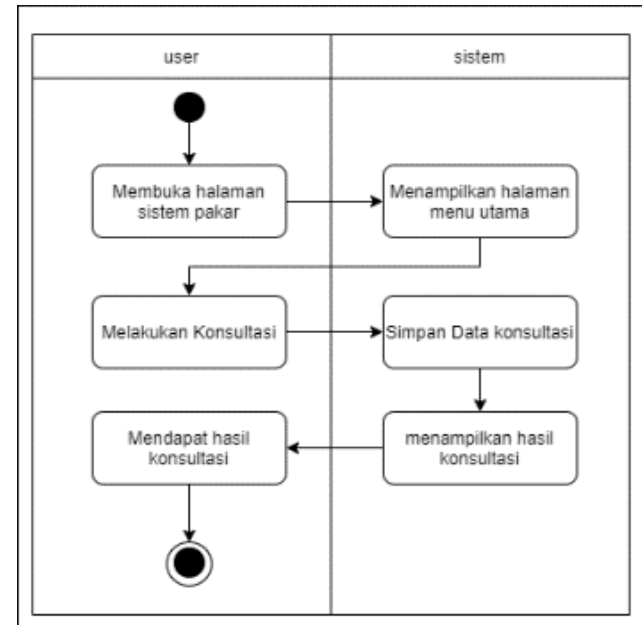

Gambar 3. Activity diagram

Gambar 3 merupakan gambar Activity diagram yang menggambarkan aktivitas dari sistem pakar pada proses diagnosa jenis kulit wajah yang menjelaskan aktivitas user dengan sistem.

\subsection{Pembuatan Sistem}

Dari desain perancangan sistem akan diimplementasikan ke dalam kode program dengan menggunakan bahasa program java menggunakan aplikasi Android Studio.

\subsection{Pengujian Sistem}

Merupakan proses yang memiliki tujuan untuk meminimalisirkan terjadinya eror dan menghasilkan output yang sesuai dan berjalan dengan baik. Pengujian sistem dilaksanakan menggunakan black-box testing yaitu pengujian validasi sistem.

\section{HASIL DAN PEMBAHASAN}

\subsection{Analisis Data}

Berdasarkan hasil pengumpulan data dari referensi jurnal penelitian dan ahli pakar dari Klinik Kecantikkan xxx, maka diperoleh 5 jenis kulit wajah pada manusia serta 32 gejala dari permasalahan kulit wajah.

Tabel 1. Jenis kulit wajah

\begin{tabular}{cc}
\hline Kode Jenis Kulit Wajah & Jenis Kulit Wajah \\
\hline P01 & Kulit Normal \\
P02 & Kulit Berminyak \\
P03 & Kulit Kering \\
P04 & Kulit Kombinasi \\
P05 & Kulit Sensitif \\
\hline
\end{tabular}

Sumber: Data Primer

Berdasarkan tabel 1, terdapat 5 jenis kulit wajah pada manusia yaitu kulit normal, kulit berminyak, kulit kering, kulit kombinasi, dan yang terakhir kulit sensitif yang telah ditentukan oleh pakar.

Tabel 2. Daftar Gejala

\begin{tabular}{cl}
\hline $\begin{array}{c}\text { Kode } \\
\text { Gejala }\end{array}$ & \\
\hline G1 & Saya merasa kulit wajah saya tidak berminyak \\
G2 & Saya merasakan tekstur wajah saya tampak halus \\
G3 & Makeup mudah menempel diwajah saya ketika saya menggunakannya \\
G4 & Saya merasa kulit saya sehat \\
G5 & Tidak ada jerawat diwajah saya \\
G6 & Saya mudah dalam memilih makeup \\
G7 & Saya merasa pori-pori saya besar di area T-Zone
\end{tabular}


JURNAL MEDIA INFORMATIKA BUDIDARMA

Volume 5, Nomor 1, Januari 2021, Page 74-82

ISSN 2614-5278 (media cetak), ISSN 2548-8368 (media online)

Available Online at https://ejurnal.stmik-budidarma.ac.id/index.php/mib

DOI 10.30865/mib.v5i1.2591

\begin{tabular}{|c|c|}
\hline $\begin{array}{l}\text { Kode } \\
\text { Gejala }\end{array}$ & Gejala \\
\hline G8 & Kulit saya tampak mengkilat \\
\hline G9 & Wajah saya sering timbul jerawat \\
\hline G10 & Saya memiliki permasalahan whitehead (komedo putih) \\
\hline G11 & Pori-pori diwajah saya sangat kecil \\
\hline G12 & Saya memiliki tekstur kulit wajah yang tipis \\
\hline G13 & Kulit wajah saya cering muncul kerutan \\
\hline G14 & Sebagian wajah saya berminyak \\
\hline G15 & Sebagian kulit saya kering \\
\hline G16 & Kulit saya sering mengalami jerawat \\
\hline G17 & Makeup sulit menempel diwajah saya \\
\hline G18 & $\begin{array}{l}\text { Saya sering mengalami alergi (gatal/ruam) di wajah ketika menggunakan } \\
\text { produk baru }\end{array}$ \\
\hline G19 & Kulit wajah saya mudah mengalami iritasi \\
\hline G20 & Kulit wajah saya mudah memerah \\
\hline G21 & Pembuluh darah kadang terlihat dari permukaan kulit wajah saya \\
\hline G22 & $\begin{array}{l}\text { Kulit saya akan mengalami breakout jika saya menggunakan produk skincare } \\
\text { baru }\end{array}$ \\
\hline G23 & Saya memiliki permasalahan blackhead diwajah saya \\
\hline $\mathrm{G} 24$ & Ketika saya bangun tidur, wajah saya tampak mengkilap \\
\hline $\mathrm{G} 25$ & $\begin{array}{l}\text { Kulit saya akan berminyak jika beberapa menit setelah menggunakan facial } \\
\text { wash }\end{array}$ \\
\hline G26 & $\begin{array}{l}\text { Ketika saya menggunakan makeup setelah beberapa jam, makeup akan luntur } \\
\text { di bagian T-Zone }\end{array}$ \\
\hline $\mathrm{G} 27$ & Saya merasa wajah saya tampak kusam \\
\hline G28 & Wajah saya akan gatal jika terkena sinar matahari \\
\hline G29 & Kulit saya mengalami Luka Bakar jika saya terpapar sinar matahari \\
\hline G30 & Jika wajah Saya terkena sinar matahari kulit saya akan Menggelap begitu cepat \\
\hline G31 & Kulit saya terasa kering setelah menggunakan facial wash \\
\hline
\end{tabular}

\section{Sumber : Data Primer}

Tabel 2 berisi 31 gejala yang didapatkan dari berbagai masalah terkait kulit wajah yang dijadikan sebagai data gejala jenis kulit wajah yang sudah ditentukan oleh pakar dan juga dari jurnal penelitian sebagai referensi.

\subsection{Certainty Factor}

Penelitian dilakukan tahapan untuk melakukan proses diagnosa jenis kulit wajah dengan menggunakan metode Certainty Factor yang dimulai dengan membuat bobot dari masing-masing gejala yang digunakan untuk mencari tingkat akurasi dari hasil diagnosa jenis kulit wajah. Berikut alur untuk menyelesaikan masalah dengan menggunakan metode certainty factor:

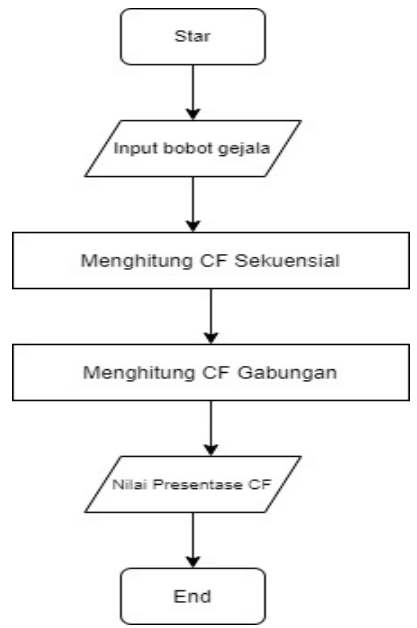

Gambar 4. Alur perhitungan metode $\mathrm{CF}$

Berikut nilai tingkat keyakinan CF (Rule) yang didapat dari interprestasi 'term' dari hasil wawancara dengan pakar yang diubah menjadi nilai $\mathrm{CF}$ tertentu sesuai dengan tabel berikut: 
JURNAL MEDIA INFORMATIKA BUDIDARMA

Volume 5, Nomor 1, Januari 2021, Page 74-82

ISSN 2614-5278 (media cetak), ISSN 2548-8368 (media online)

Available Online at https://ejurnal.stmik-budidarma.ac.id/index.php/mib DOI 10.30865/mib.v5i1.2591

Tabel 3. Interprestasi (term) Certainty Factor

\begin{tabular}{cc}
\hline Certainty Term & Certainty Factor \\
\hline Pasti Tidak & 0 \\
Tidak Yakin & 0.2 \\
Sedikit Yakin & 0.4 \\
Cukup Yakin & 0.6 \\
Yakin & 0.8 \\
Sangat Yakin & 1 \\
\hline
\end{tabular}

Tabel 3 menjelaskan nilai bobot dari metode certainty factor dengan menggunakan 6 bobot yang digunakan yaitu $0,0.2,0.4,0.6,0.8$, dan 1 . Semiakin besar bobot, semakin besar juga nilai keyakinan dari gejala tersebut.

\subsection{Forward Chaining}

Pada teknik perhitungan persentase keyakinan di mulai dengan sebuah kaidah (rule) yang meiliki berbagai macam gejala kemudian terbentuklah kaidah-kaidah (rules) yang dijadikan acuan dalam menentukan diagnosa yang diderita oleh user.

Pada proses ini melibatkan teknik forward chaininng yang digunakan untuk mencari kesimpulan berdasarkan sebab-akibat dengan menggunakan aturan IF-THEN dan juga teknik certainty factor untuk memberi nilai bobot (CF Pakar) yang sudah ditentukan oleh pakar.

Tabel 4. Rule dan Nilai Certainty Factor Pakar

\begin{tabular}{|c|c|}
\hline Rule Ke & Rules \\
\hline 1 & $\begin{array}{l}\text { IF [G1:0.8] AND [G2:0.8] AND [G3 : 0.8] AND [G4: : 0.8] AND [G5: 0.8] AND [G6 : 0.8] } \\
\text { AND [G11:0.8] AND [G30:0.4] THEN P01 }\end{array}$ \\
\hline 2 & $\begin{array}{l}\text { IF [G7 : 0.8] AND [G8:0.8] AND [G9:0.8] AND [G16: } 0.8] \text { AND [G23:0.8] AND [G24 } \\
: 0.8] \text { AND [G25: 0.6] AND [G26: 0.8] AND [G27:0.6] THEN P02 }\end{array}$ \\
\hline 3 & $\begin{array}{l}I F[\mathrm{G} 1: 0.6] \text { AND [G5:06] } A N D[\mathrm{G} 10: 0.8] \text { AND [G11 : 06] AND [G12: 0.6] AND [G13: } \\
0.8] \text { AND [G20:0.2] AND [G27: 0.8] AND [G30:0.4] AND [G31:0.8] THEN P03 }\end{array}$ \\
\hline 4 & $\begin{array}{l}\text { IF [G7: 0.6] AND [G14:0.8] AND [G15:0.8] AND [G16:0.4] AND [G17: 0.8] AND [G23 } \\
: 0.8] A N D[\mathrm{G} 25: 0.6] A N D[\mathrm{G} 26: 0.6] \text { THEN P04 }\end{array}$ \\
\hline 5 & $\begin{array}{l}\text { IF [G9 : 0.8] AND [G12:0.8] AND [G18: 0.8] AND [G19:0.8] AND [G20:0.8] AND [G21: } \\
0.6] \text { AND [G22: 0.8] AAND [G28: 0.6] AND [G29: 0.6] THEN P05 }\end{array}$ \\
\hline
\end{tabular}

Sumber : Data Primer

Tabel 4 merupakan tabel yang berisi 5 rules dari teknik forward chaining sesuai dengan jenis kulit wajah. Dimana setiap jenis kulit memiliki rules yang berbeda-beda.

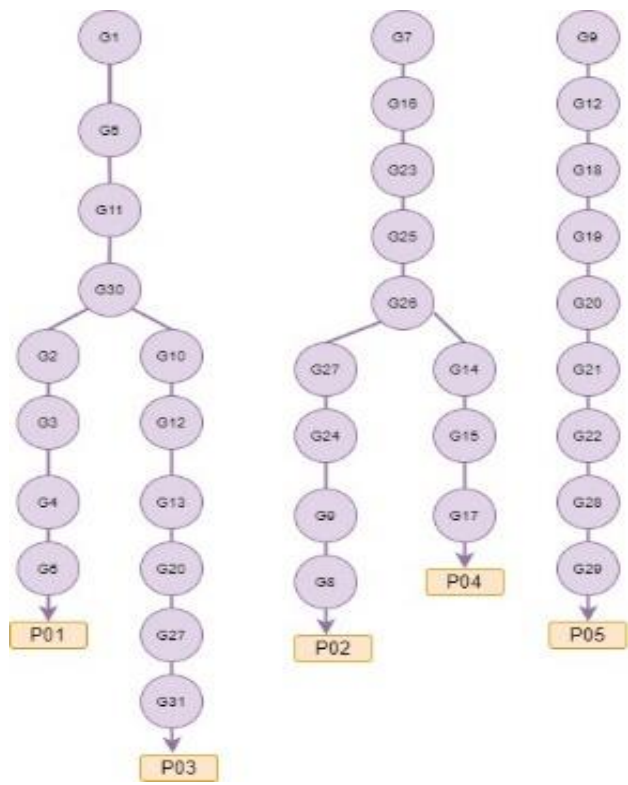

Gambar 5. Pohon Pakar

Pada gambar 5 merupakan gambar dari pohon keputusan (pohon pakar) berdasarkan teknik forward chaining dari inferensi sistem pakar untuk mengidentifikasi jenis kulit wajah dan rules yang sudah ditentukan oleh pakar. 
JURNAL MEDIA INFORMATIKA BUDIDARMA

Volume 5, Nomor 1, Januari 2021, Page 74-82

ISSN 2614-5278 (media cetak), ISSN 2548-8368 (media online)

Available Online at https://ejurnal.stmik-budidarma.ac.id/index.php/mib DOI 10.30865/mib.v5i1.2591

\subsection{Uji Coba}

Berikut tabel yang berisi sample dari Klinik Kecantikan xxx:

Tabel 5. Sampel data dari Klinik Kecantikan Xxx

\begin{tabular}{|c|c|c|}
\hline Data No & Jenis Kelamin & Kode Gejala \& CF User \\
\hline 1 & Perempuan & G1[0.6]; G2[0.8]; G3[0.6]; G4[0.8]; G5[0.8]; G6[0.2]; G11[0.4]; G30[0.6]; \\
\hline 2 & Perempuan & $\begin{array}{l}\text { G7[0.6]; G8[0.4]; G9[0.2]; G14[0.8]; G15[0.6]; G16[0.4]; G17[0.4]; G23[0.6]; } \\
\text { G25[0.6]; G26[0.8]; }\end{array}$ \\
\hline 3 & Perempuan & $\begin{array}{l}\text { G1[1]; G5[0.2]; G10[0.6]; G11[0.4]; G12[0.4]; G13[0.6]; G20[0.2]; G27[0.4]; } \\
\text { G30[0.4]; G31[0.2]; }\end{array}$ \\
\hline 4 & Perempuan & $\begin{array}{l}\text { G7[0.4]; G8[0.6]; G9[0.6]; G16[0.4]; G23[0.4]; G24[0.6]; G25[0.6]; G26[0.4]; } \\
\text { G27[0.4]; }\end{array}$ \\
\hline 5 & Perempuan & $\begin{array}{l}\text { G9[0.2]; G12[0.4]; G18[0.2]; G19[0.2]; G20[0.6]; G21[0.8]; G22[0.8]; G28[0.2]; } \\
\text { G29[0.2]; }\end{array}$ \\
\hline
\end{tabular}

Pada tabel 5 dari data yang telah diketahui dari tabel 2, Data No 1 telah memilih 11 gejala yang sesuai dialami oleh user itu sendiri dan memilih nilai sesuai tingkat keyakinannya.

Setelah ditelaah terhadap semua rule yang dipilih oleh user maka proses perhitungan menggunakan rule ke satu, karena dari semua rule yang ada rule ke satu yang telah terpenuhi. Maka tahap selanjutnya berdasarkan rule kesatu dilakukan proses perhitungan menggunakan metode certainty factor sebagai berikut:

Rule ke $1=I F[\mathrm{G} 1: 0.8]$ AND [G2: 0.8] AND [G3 : 0.8] AND [G4 : 0.8] AND [G5 : 0.8] AND [G6 : 0.8] AND [G11 : 0.8] AND [G23:0.4] AND [G30 : 0.4] THEN P01

Tabel 6. Perhitungan certainty factor sekuensial dari data no. 1

\begin{tabular}{cccc}
\hline Kode Gejala & CF Pakar & CF User & Hasil \\
\hline G1 & 0.8 & 0.6 & 0.48 \\
G2 & 0.8 & 0.8 & 0.64 \\
G3 & 0.8 & 0.6 & 0.48 \\
G4 & 0.8 & 0.8 & 0.64 \\
G5 & 0.8 & 0.8 & 0.64 \\
G6 & 0.8 & 0.2 & 0.16 \\
G11 & 0.8 & 0.4 & 0.32 \\
G30 & 0.4 & 0.6 & 0.24 \\
\hline
\end{tabular}

Setelah mendapatkan nilai CF maka tahap selanjutnya menghitung nilai CF gabungan dengan menggunakan persamaan (3) karena memiliki lebih dari 1 gejala. Berikut perhitungan CF gabungan:

Tabel 7. Perhitungan certainty factor sekuensial dari data no. 1

\begin{tabular}{cc}
\hline Iterasi/ Hasil & CFgabungan $=C F 1+C F 2 \times(1-C F 1)$ \\
\hline 1 & $0.48+0.64 *(1-0.48)=0.8128$ \\
2 & $0.8128+0.48 *(1-0.8128)=0.9027$ \\
3 & $0.9027+0.64 *(1-0.9027)=0.9649$ \\
4 & $0.9649+0.64 *(1-0.9649)=0.9874$ \\
5 & $0.9874+0.16 *(1-0.9874)=0.9894$ \\
6 & $0.9894+0.32 *(1-0.9894)=0.9928$ \\
7 & $0.9928+0.24 *(1-0.9928)=0.9945$ \\
Hasil & $0.9954 * 100 \%=99.45 \%$ \\
\hline
\end{tabular}

Hasil CF combine terakhir merupakan hasil dari diagnosa yang menentukan jenis kulit wajah dengan menggunakan perhitungan Certainty factor dan karena rule ke satu yang terpenuhi dengan menggunakan kaidah teknik Forward chaining, Maka hasil diagnosa dari data no. 1 menyatakan bahwa user memiliki jenis kulit wajah normal dengan tingkat keyakinan $99.45 \%$. Adapun hasil pengujian data lain dari gejala yang dipilih user pada tabel no. 5 .

Tabel 8. Perhitungan Hasil CF Sistem dan CF Manual

\begin{tabular}{cccc}
\hline $\begin{array}{c}\text { Data } \\
\text { No }\end{array}$ & $\begin{array}{c}\text { Hasil CF } \\
\text { Sistem }\end{array}$ & Hasil CF Manual & Jenis Kulit \\
\hline 1 & $99.45 \%$ & $99.45 \%$ & Wajah normal \\
2 & $98.82 \%$ & $98.82 \%$ & Wajah kombinasi \\
3 & $97.47 \%$ & $97.47 \%$ & Wajah kering \\
4 & $98.54 \%$ & $98.54 \%$ & Wajah berminyak \\
5 & $96.96 \%$ & $96.96 \%$ & Wajah sensitif \\
\hline
\end{tabular}




\section{JURNAL MEDIA INFORMATIKA BUDIDARMA}

Volume 5, Nomor 1, Januari 2021, Page 74-82

ISSN 2614-5278 (media cetak), ISSN 2548-8368 (media online)

Available Online at https://ejurnal.stmik-budidarma.ac.id/index.php/mib DOI 10.30865/mib.v5i1.2591

Tabel 8 merupakan hasil perhitungan CF sistem dengan CF manual, dimana hasil perhitungan CF baik menggunakan sistem maupun manual menghasilkan nilai yang sesuai dan hasil diagnosa jenis kulit wajah dengan menggunakan teknik forward chaining sesuai dengan rules yang telah ditentukan.

\subsection{Implementasi}

Dalam membangun sistem pakar yang dapat digunakan oleh user pastinya dibutuhkan user interface yang dapat mempermudah user untuk mengetahui jenis kulit wajah, aplikasi sitem pakar tersebut dibuat menggunakan kombinasi metode certainty factor dengan teknik forward chaining menggunakan bahasa pemograman java.

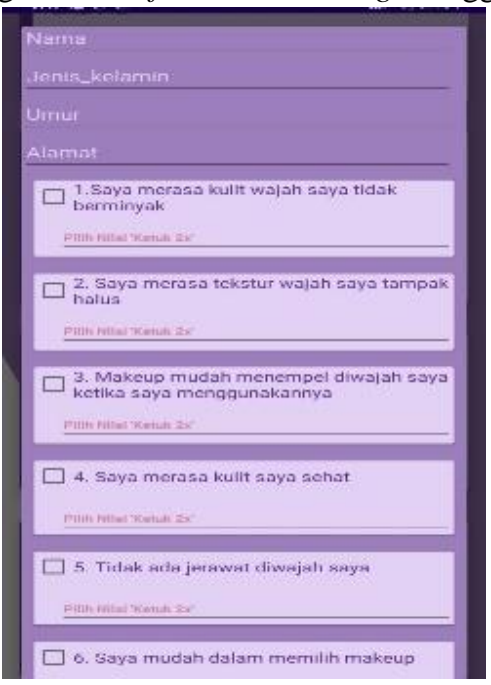

Gambar 6. Menu Konsultasi

Gambar 6 merupakan tampilan menu konsultasi yang dapat diakses oleh user. User memilih gejala dengan memberi checklist pada gejala yang dialami dengan memilih iya atau tidak, jika iya maka pilihlah nilai CF user yang sesuai dengan tingkat keyakinan user.

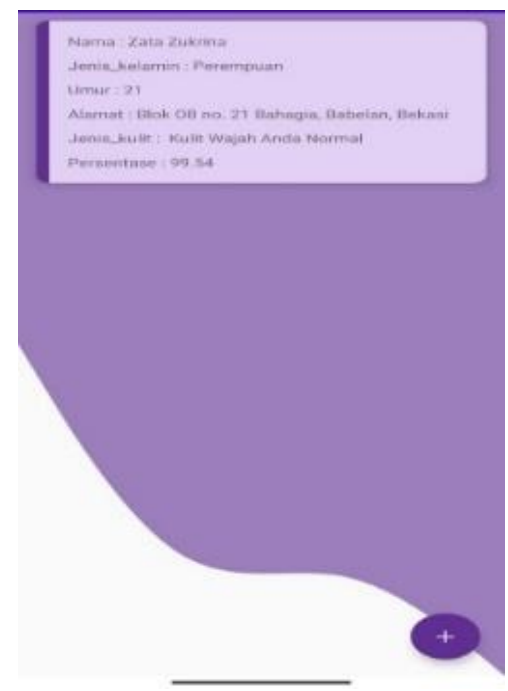

Gambar 7. Halaman Hasil Diagnosa

Gambar 7 merupakan tampilan hasil diagnosa setelah user memilih gejala yang dialami, maka proses selanjutnya yaitu user mendapat hasil konsultasi. Hasil dari konsultasi akan menentukan jenis kulit wajah dan presentase serta data diri yang sudah di isi pada menu konsultasi.

\section{KESIMPULAN}

Hasil perhitungan yang dilakukan untuk menentukan jenis kulit wajah dengan menggunakan aplikasi sistem pakar dan hasil perhitungan yang dilakukan secara manual menghasilkan tingkat keyakinan dan jenis kulit yang sama, salah satunya data no. 1 pada sistem menghasilkan tingkat keyakinan sebesar $99.45 \%$ dan pada perhitungan manual juga menghasilkan $99.45 \%$ dengan menggunakan metode certainty factor serta jenis kulit wajah pada data no.1 menghasilkan jenis kulit wajah normal dengan menggunakan teknik forward chaining. Maka dapat 


\section{JURNAL MEDIA INFORMATIKA BUDIDARMA}

Volume 5, Nomor 1, Januari 2021, Page 74-82

ISSN 2614-5278 (media cetak), ISSN 2548-8368 (media online)

Available Online at https://ejurnal.stmik-budidarma.ac.id/index.php/mib DOI 10.30865/mib.v5i1.2591

disimpulkan bahwa kombinasi metode certainty factor dengan teknik forward chaining sangat mungkin untuk diterapkan pada sistem pakar dalam upaya membantu pengguna untuk mengetahui jenis kulit wajah.

\section{REFERENCES}

[1] R. Pebrianto, S. N. Nugraha, and W. Gata, "Perancangan Sistem Pakar Penentuan Jenis Kulit Wajah Menggunakan Metode Certainty Factor," IJCIT (Indonesian J. Comput. Inf. Technol., vol. 5, no. 1, pp. 83-93, 2020, doi: 10.31294/ijcit.v5i1.7408.

[2] S. A. Wulandari, W. A. Prasetyanto, and M. D. Kurniatie, "Classification of Normal, Oily and Dry Skin Types Using a 4- Connectivity and 8-Connectivity Region Properties Based on Average Characteristics of Bound," J. Transform., vol. 17, no. 01, pp. 78-87, 2019.

[3] J. Y. Hong, S. J. Park, S. J. Seo, and K. Y. Park, “Oily sensitive skin: A review of management options,” J. Cosmet. Dermatol., vol. 19, no. 5, pp. 1016-1020, 2020, doi: 10.1111/jocd.13347.

[4] O. A. Oninla, S. O. Oninla, B. I. Otike-Odibi, M. M. Oripelaye, F. O. Olanrewaju, and T. Mohammed, "African Skin: Different Types, Needs and Diseases," Int. J. Trop. Dis. Heal., vol. 36, no. 3, pp. 1-13, 2019, doi: 10.9734/ijtdh/2019/v36i330143.

[5] I. H. Santi and B. Andari, "Sistem Pakar Untuk Mengidentifikasi Jenis Kulit Wajah dengan Metode Certainty Factor," INTENSIF J. Ilm. Penelit. dan Penerapan Teknol. Sist. Inf., vol. 3, no. 2, p. 159, 2019, doi: 10.29407/intensif.v3i2.12792.

[6] I. H. Santi and B. Andari, "Analisa Perancangan Sistem Pakar Untuk Mengidentifikasi Jenis Kulit Wajah," vol. 2, pp. 1$8,2019$.

[7] A. S. Sembiring et al., "Implementation of Certainty Factor Method for Expert System," J. Phys. Conf. Ser., vol. 1255, no. 1, 2019, doi: 10.1088/1742-6596/1255/1/012065.

[8] Y. K. Kumarahadi, M. Z. Arifin, S. Pambudi, T. Prabowo, and K. Kusrini, "Sistem Pakar Identifikasi Jenis Kulit Wajah Dengan Metode Certainty Factor," J. Teknol. Inf. dan Komun., vol. 8, no. 1, pp. 21-27, 2020, doi: 10.30646/tikomsin.v8i1.453.

[9] Y. Bin Lee et al., "Baumann skin type in the Korean male population," Ann. Dermatol., vol. 31, no. 6, pp. 621-630, 2019, doi: 10.5021/ad.2019.31.6.621.

[10] S. M. Journal, "Sumatera Medical Journal,” vol. 02, no. 01, pp. 1-6, 2019.

[11] P. S. Sukanto, R. T. Subagio, and D. C. Natalie, "Implementasi Sistem Pakar Dalam Menentukan Jenis Perawatan Kulit Wajah Menggunakan Metode Forward Chaining," Smatika J., vol. 9, no. 02, pp. 65-72, 2020, doi: 10.32664/smatika.v9i02.389.

[12] I. Sinuraya, A. Triayudi, and I. D. Sholihati, "Covid-19 Diagnosis Based Android Mobile Application using Certainty Factor Method," Sisfotenika, vol. 10, no. 2, p. 203, 2020, doi: 10.30700/jst.v10i2.968.

[13] S. Rofiqoh, D. Kurniadi, and A. Riasyah, "Sistem Pakar Diagnosa Penyakit Pada Tanaman Karet Menggunakan Metode Forward Chaining," Ranc. Bangun e-CRM pada Pasar Murah Solo, vol. 1, no. 1, pp. 54-56, 2020.

[14] J. Nasir and Z. H. Gultom, "Sistem Pakar Untuk Mendeteksi Kerusakan Pada Sepeda Motor Dengan Menggunakan Metode Forward Chaining Berbasis Web," Digit. Zo. J. Teknol. Inf. dan Komun., vol. 9, no. 1, pp. 42-58, 2018, doi: 10.31849/digitalzone.v9i1.1075.

[15] L. Safira, B. Irawan, and C. Setiningsih, "Implementation of the Certainty Factor Method for Early Detection of Cirrhosis Based on Android," J. Phys. Conf. Ser., vol. 1201, no. 1, 2019, doi: 10.1088/1742-6596/1201/1/012053.

[16] E. S. Palupi, S. M. Pahlevi, U. Bina, S. Informatika, P. Magister, and I. Komputer, "Diagnosa Depresi pada Mahasiswa Menggunakan Metode Certainty Factor dan Forward Chaining,” Inti Nusa Mandiri, vol. 14, no. 2, pp. 133-138, 2020. 